\section{Is matching performance an adequate test of "extinction" effects on individual association?}

\author{
SETH GREENBERG and DELOS D. WICKENS* \\ The Ohio State University, Columbus, Ohio 43210
}

Using an RI design, two sorts of interpolated conditions were employed. In one, bidirectional extinction was introduced ( $A-D, B-C)$, and in the other, unidirectional extinction was given $[(A-D, A-E)$ or $(A-D, E-F)]$. Retention was measured by a matching task, and it was found that bidirectional extinction was more detrimental to performance than was unidirectional extinction. The findings raise a question about the validity of rejecting the notion of the extinction of individual associations as a contributor to forgetting if only unidirectional extinction has been given, since Ss can use either backward or forward associations in the matching task. In addition, the experiment offers evidence for the loss of specific associations in the A-B, A-D type of paradigm when bidirectional extinction is employed.

During recent years, interference theory has moved away from the view that forgetting in the retroactive inhibition (RI) paradigm is due to the extinction of individual S-R associations to the view that lowered performance in recall is due to a suppression of the first-list responses as a class (Postman, Stark, \& Fraser, 1968). This view has come about, in part, because Ss do extremely well in matching the stimulus and response terms of the first list, despite the fact that they do poorly in recalling the response given the stimulus (Garskof, 1968; Garskof \& Sandak, 1964; McGovern, 1964). These findings suggest that the A-D event does not depress the specific association through an extinction (or counterconditioning) process, for if it did, the matching task would also be depressed. These results suggest that the responses as a group simply cannot be retrieved (are suppressed), for when they are given to $S$ in the matching task, he has little difficulty in pairing the appropriate stimulus and response terms.

It is apparent, however, that in a matching task wherein the stimuli are typically presented in one column and the response in another, $\mathrm{S}$ may match from stimulus term to response term or in the reverse direction. We know that during learning the association formed is at least to some degree bidirectional (Asch \& Ebenholtz, 1962). If an interpolated A-D list does not extinguish the B-A association, or does so to a lesser degree, then the backward association is still available at the time of the matching task. Thus,

\footnotetext{
* Requests for reprints should be sent to Delos D. Wickens, Psychology Dept., 1945 North High St., Ohio State University, Columbus, Ohio 43210. This research was supported in part by an NIMH grant (5TO1-MH08526).
}

one may incorrectly assume that A-B weakenings did not occur when the correct match is given, although actually it could be arrived at in the B-A order. This possibility was mentioned by Garsk of (1968).

It was the purpose of this experiment to put this logical possibility to an empirical test by using two interpolated lists an A-D and a B.C-and comparing the performance of these groups with ones given only unidirectional extinction experience in IL.

\section{DESIGN}

There were seven major groups in the experiment, all of whom learned the first list (OL) and all of whom were given the same matching test immediately after the interpolated learning (IL). The groups differed from each other in the nature of the interpolated task. The IL activities for each group are shown in Table 1 and are described below. The list for $O L$ was $\mathrm{A}-\mathrm{B}$ for half the $\mathrm{Ss}$ and $\mathrm{B}-\mathrm{A}$ for the other half. Table 1 shows the IL activities for the Ss who learned an A-B list in OL. Suitably rearranged versions of the IL lists provided equivalent types of extinction for the Ss whose OL list was B-A.

\section{Bidirectional}

The major characteristics of these groups is that both the forward and backward associations underwent extinction during OL, with eight trials on each list. The two major subgroups in the experiment are distinguished by $F$ and $B$ in the results, and they differ only in whether the association was extinguished in the C-B or the B-C order. Since it is quite difficult to justify one of these methods as being more appropriate than the other, both were used. The results showed no difference in effectiveness between these two conditions. It should be noted that Postman, Stark, \& Henschel (1969) found identical performance for these two groups in immediate recall, the retention interval used in this experiment. In summary, then, the conception leading to the formation of this group was to give extinction trials in both the forward and backward direction.

\section{Unidirectional}

The two subgroups in this larger group received the same number of forward extinction trials or backward extinction trials as did any of the bidirectional groups, their remaining trials being upon a list containing new stimuli and new responses. Thus, these groups experienced either stimalus or response extinction to the same amount as a bidirectional group, but not both.

Double Unidirectional

It might be argued that any difference in performance between the above unidirectional group and the bidirectional group was due to the fact that the bidirectional group experienced 16 trials with one or the

Table 1

Schematic Description of Procedure

\begin{tabular}{|c|c|c|c|}
\hline \multirow[b]{2}{*}{ Group } & \multicolumn{2}{|c|}{ Interpolated Task } & \multirow[b]{2}{*}{$\mathbf{N}$} \\
\hline & IL1 & IL 2 & \\
\hline $\begin{array}{l}\text { Bidirectional } \\
\text { Forward (F) } \\
\text { Backward (B) }\end{array}$ & $\begin{array}{l}8 \text { Trials } \\
\text { A-D } \\
\text { A-D }\end{array}$ & $\begin{array}{l}8 \text { Trials } \\
\text { B-C } \\
\text { C-B }\end{array}$ & $\begin{array}{l}24 \\
24\end{array}$ \\
\hline $\begin{array}{l}\text { Unidirectional } \\
\text { Response Extinction (R) } \\
\text { Stimulus Extinction (S) }\end{array}$ & $\begin{array}{l}8 \text { Trials } \\
A \cdot D\end{array}$ & $\begin{array}{l}8 \text { Trials } \\
\text { E-F }\end{array}$ & 24 \\
\hline $\begin{array}{l}\mathbf{a} \\
\mathbf{b}\end{array}$ & $\begin{array}{l}\mathrm{C}-\mathrm{B} \\
\mathrm{B} \cdot \mathrm{C}\end{array}$ & $\begin{array}{l}\mathbf{E} \cdot \mathbf{F} \\
\mathbf{E} \cdot \mathbf{F}\end{array}$ & $\begin{array}{l}12 \\
12\end{array}$ \\
\hline $\begin{array}{l}\text { Double Unidirectional } \\
\text { Response Extinction (R) } \\
\text { Stimulus Extinction (S) }\end{array}$ & $\begin{array}{l}8 \text { Trials } \\
A-D\end{array}$ & $\begin{array}{l}8 \text { Trials } \\
\text { A-E }\end{array}$ & 24 \\
\hline $\begin{array}{l}\mathbf{a} \\
\mathbf{b}\end{array}$ & $\begin{array}{l}\mathrm{C} \cdot \mathrm{B} \\
\mathrm{B} \cdot \mathrm{C}\end{array}$ & $\begin{array}{l}\mathrm{E}-\mathrm{B} \\
\mathrm{B}-\mathrm{E}\end{array}$ & $\begin{array}{l}12 \\
12\end{array}$ \\
\hline Control & $\begin{array}{l}8 \text { Trials } \\
\text { C-D }\end{array}$ & $\begin{array}{l}8 \text { Trials } \\
\text { E-F }\end{array}$ & 24 \\
\hline
\end{tabular}


Matching Test Performance

\begin{tabular}{|c|c|c|c|c|c|c|}
\hline \multirow{2}{*}{$\underbrace{\text { Condition }}_{\text {Bidirectional }}$} & \multirow{2}{*}{$\frac{\text { Group }}{\text { B }}$} & \multirow{2}{*}{$\begin{array}{c}\text { Total } \\
\text { Errors } \\
47\end{array}$} & \multirow{2}{*}{$\begin{array}{c}\begin{array}{c}\text { Average } \\
\text { Errors } \\
\text { Per S }\end{array} \\
1.96\end{array}$} & \multirow{2}{*}{$\begin{array}{l}\begin{array}{l}\text { SD of } \\
\text { Errors }\end{array} \\
2.00\end{array}$} & \multicolumn{2}{|c|}{$\begin{array}{c}\text { Number of Ss } \\
\text { Committing } \\
\text { Errors }\end{array}$} \\
\hline & & & & & 13 & $54 \%$ \\
\hline Bidirectional & $\mathbf{F}$ & 45 & 1.87 & 1.77 & 14 & $58 \%$ \\
\hline Unidirectional & $\mathbf{R}$ & 14 & .58 & 1.22 & 4 & $17 \%$ \\
\hline Unidirectional & $\mathbf{S}$ & 11 & .46 & 1.08 & 5 & $21 \%$ \\
\hline Double Unidirectional & $\mathbf{R}$ & 24 & 1.00 & 1.32 & 8 & $33 \%$ \\
\hline Double Unidirectional & $\mathbf{S}$ & 24 & 1.00 & 1.47 & 10 & $42 \%$ \\
\hline Control & & 2 & .08 & .13 & 1 & $4 \%$ \\
\hline
\end{tabular}

other term of the first list, while the unidirectional groups experienced only 8 , and it was the total amount of this experience, rather than the bidirectionality, which produced the difference. The double unidirectional groups were used to equate the number of times a first-list term was used in IL but to extinguish in only one direction. Again, both C-B and B-C were employed.

\section{Control}

The control group received the same number of interpolated trials on two lists as did the other groups, but neither IL list included any of the first-list terms.

\section{SUBJECTS}

There were 24 Ss in each of the seven groups of the experiment. They chose this experiment to meet a part of their course requirement in elementary psychology and were assigned randomly to groups.

\section{PROCEDURE}

The lists were presented at a 2:2-sec rate on a memory drum, with a $4-\mathrm{sec}$ intertrial interval and a 2-min interlist interval. All lists were learned by the standard anticipation method. The first list was learned to a criterion of one perfect trial, after which Ss received $8 \mathrm{IL}-1$ and $8 \mathrm{IL}-2$ trials. The two interpolated lists were presented alternately in series of 5 , then 2 , and finally 1 trial. Thus, the bidirectional-forward group received 5 A-D trials, followed by 5 B-C trials, 2 more A-D trials, 2 B-C trials, 1 A-D trial, and finally 1 B-C trial. The purpose of the alternation procedure was to attempt to cause each list to be of equal strength at the time of the matching test on List 1 . Half of the groups started with one condition and half with the other. Following the last IL trial, a matching test, which contained the stimulus words from the OL list in one column and the response words in the second column, was given. The columns of words were constructed randomly, with the restriction that no stimulus word appear adjacent to its appropriate response term.

Six individual lists, composed of 10 noun pairs, were required to form the various PA lists. A total of 60 different high-frequency nouns selected from 60 different taxonomic categories was used. The individual lists were constructed so as to eliminate obvious interlist associations. Similarly, an attempt was made to avoid high associative pairs when the lists were constructed. Four random orders of the 10 pairs were constructed for each list to reduce the opportunity for serial learning.

\section{RESULTS}

An analysis of variance of the number of trials to reach OL criterion indicated comparable performance for the seven groups: $F(6,161)=1.66$, with the lowest mean being 7.33 and the highest 10.58 trials. The lowest of these means was that of the control group, and the highest was that of the unidirectional stimulus-extinction group.

The basic results of the matching test are presented in Table 2. This table shows the mean error score, its standard deviation, and the number of Ss who committed at least one error on the test. An ANOVA on matching test errors demonstrated that the groups were significantly different, $\mathrm{F}(6,161)=5.78, \mathrm{p}<.001$. A New man-Keuls (Winer, 1962 , pp. 85-89) post hoc analysis revealed that Ss in both bidirectional groups committed significantly more errors than Ss in the unidirectional groups and the control group. The pattern held true for both the .05 and .01 levels of significance. There was no significant difference for any other group comparisons, though the comparison between the bidirectional groups and the double-unidirectional interference groups approached significance $(p<.10)$. In addition, one notes in Table 2 that approximately three times as many Ss committed matching errors in the bidirectional groups as in the unidirectional groups, while only one $\mathrm{S}$ committed errors in the control group. Thus, both the number of errors per $S$ and the number of Ss making errors increased substantially in the double interference group.

\section{DISCUSSION}

The purpose of this experiment was to inquire into the possibility that matching test performance does not give unequivocal evidence concerning the strength of individual associations in an $A-B, A-D$ retroactive inhibition design. The rationale for the research was that during the matching activity, $S$, if he had experienced an A-D design, might have intact B-A associations available to aid him in this activity. Similarly, if he had experienced a $C$ - $B$ interference situation, he might retain A-B associations and match on this basis.

The results of the experiment lends support to this interpretation. The groups given "extinction" trials in both directions were significantly $(p<.05)$ inferior to the groups given $\mathrm{A}-\mathrm{D}+\mathrm{E}-\mathrm{F}$ or C-B (B-C) + E-F, namely, the groups that received extinction trials in only one direction, response or stimulus. This was true even though the number of interpolated learning trials was the same for all groups.

It might be stated that the appropriate comparison for the bidirectional groups should be with the groups which received all of their interpolated learning in either the forward or the backward extinction paradigm. If this is the proper set of comparisons, the data are not quite as strong, since the $\mathrm{p}$ reaches the $<.10$ level rather than the customary $<.05$ level between the bidirectional and the double-unidirectional groups. However, the difference is close enough to significance to strongly caution one against accepting the null hypothesis and concluding that the two conditions were alike in their effect upon the matching task.

It should be noted also that the results are markedly consistent. The two bidirectional groups produced approximately the same number of errors, and the double-unidirectional groups were exactly alike in error production, with the error rate being nearly twice as great for the bidirectional group. The significantly inferior performance of the bidirectional groups to the control group certainly argues for an additional interference mechanism as opposed to response suppression alone. In particular, it argues for a loss of individual associations.

A point of further interest is the fact that the $A-D$ and the $B-C$ (C-B) procedures have just about equal effect on the matching task. This holds true for all of the paired groups in the experiment, and it suggests that the two conditions work in essentially the same manner.

The rank ordering of the results of this experiment can be readily understood if it is assumed that response and stimulus extinction effects are not symmetrical-that while one is undergoing extinction, the other loses strength to a lesser degree. As a consequence, both unidirectional 
groups performed better on the matching task than did the bidirectional group, presumably because some information is available from the nondirectly extinguished connection. The work of Johnston (1967) and of Petrich (1970) lend evidence to the nonsymmetrical position.

Parenthetically, several of the protocols obtained in the experiment lend support to the view that Ss may use associations in the direction opposite from the IL extinction direction. In the matching task, the stimulus and response terms were presented in columns and $\mathrm{Ss}$ were asked to draw lines between the paired words. In some cases, Ss added an arrow tip to their lines, presumably indicating the direction of the association. A fair number of these instances occurred for the single interference groups in a direction opposite from the IL extinction direction, thus implying that the reversed association was being used.

In a recent study by Merryman (1971), a similar question has been raised on the use of the multiple-choice test, where once again $S$, during the retention test, is free to associate in either the backward or the forward direction. He, too, found evidence which is consonant with the basic conceptual findings of the present research.

As has been pointed out earlier, the dominant data which have given credence to the response suppression interpretation as the exclusive mechanism responsible for $\mathrm{RI}$ have been studies using the matching task or the multiple-choice method.

The present study, as well as the Merryman study, would indicate that procedures which fail to eliminate bidirectional associations are not adequate for testing the effect of interpolated learning on individual associations. Obviously, this reservation does not apply to the A-B C-D paradigm.

\section{REFERENCES}

ASCH, S. E., \& EBENHOLTZ, S. M. The principle of association symmetry. Proceedings of the American Philosophical Society, 1962, 106. 135-163.
GARSKOF, M, H. Short-term retention of paired-associates as a function of instruction and retention measure. Journal of Verbal Learning \& Verbal Behavior, 1968, 7, 409-412.

GARSKOF, B. E, SANDAK, J. M. \&z MALINOWSKI, E. W. A. Controlling the "fate" of first list associates. Psychonomic Science, 1965, 2, 315-316.

JOHNSTON, W. A. S-R, R-S independence and the interference potency of latent $\mathrm{R}-\mathrm{S}$ associations. Journal of Experimental Psychology, 1967, 74,511-516.

MCGOVERN, J. B. Extinction of associations in four transfer paradigms. Psychological Monographs, 1964, 78(16. Whole No.593)

MERRYMAN. C. T. Retroactive inhibition in the A-B. A-D paradigm as measured by a multiple-choice test. Journal of Experimental Psychology, 1971, 91, 212-214.

PETRICH, J. A. S-R and R-S unlearning as a function of transfer paradigm. Journal of Experimental Psychology, 1970, 83, $19-24$.

POSTMAN, L., STARK, K., \& FRASER, J. Temporal changes in interference. Journal of Verbal Learning \& Verbal Behavior, $1968,7,672-694$.

POSTMAN, L., STARK, K., \& HENSCHEL, D. Conditions of recovery after unlearning. Journal of Experimental Psychology, 1969, 82 (1, Pt. 2), 1-24.

WINER, B. J. Statistical principles in experimental design. New York: McGraw-Hill, 1962. 